\title{
BMJ Open Psychological distress among mountainous farmers in Vietnam: a cross-sectional study of prevalence and associated factors
}

\author{
Men Thi Hoang, ${ }^{1,2}$ Khanh Nam Do, ${ }^{3}$ Hai Quang Pham (1) , ${ }^{1,4}$ Cuong Tat Nguyen, ${ }^{1,4}$ \\ Giang Hai Ha (1) , ${ }^{1,2}$ Giang Thu Vu, ${ }^{5}$ Bach Xuan Tran, ${ }^{3,6}$ Carl Latkin, ${ }^{6}$ \\ Roger C M Ho (i) , ${ }^{7,8}$ Cyrus $\mathrm{SH} \mathrm{Ho}^{9}$
}

To cite: Hoang MT,

Do KN, Pham HQ, et al. Psychological distress among mountainous farmers in Vietnam: a cross-sectional study of prevalence and associated factors. BMJ Open 2020;10:e038490. doi:10.1136/ bmjopen-2020-038490

- Prepublication history for this paper is available online. To view these files, please visit the journal online (http://dx.doi org/10.1136/bmjopen-2020038490).

Received 12 March 2020 Revised 25 June 2020 Accepted 30 June 2020
Check for updates

(C) Author(s) (or their employer(s)) 2020. Re-use permitted under CC BY-NC. No commercial re-use. See rights and permissions. Published by BMJ.

For numbered affiliations see end of article.

Correspondence to

Giang Hai Ha;

hahaigiang@duytan.edu.vn

\section{ABSTRACT}

Background Psychological distress has been known as a major health problem among farmers across the world. In Vietnam, approximately $50 \%$ of farmers have lived in rural and mountainous areas. Yet, little has been known about how psychological distress impacts mountainous farmers' health. Objectives This study aimed to examine the prevalence and risk factors related to psychological distress among mountainous farmers in Vietnam.

Design and setting A cross-sectional study was performed from August to September 2018 in Moc Chau district, Vietnam. A structured questionnaire and face-toface interviews were used for data collection.

Participants A random sample of 197 farmers aged at least 18 years, spoke Vietnamese, was not suffering from severe diseases and residing in Moc Chau at the time of the survey were recruited.

Primary and secondary outcome measures The Kessler Psychological Distress Scale (K6) was employed to measure psychological distress. The tobit and logistic regressions were applied to indicate associated factors. Results The prevalence of psychological distress was $38.2 \%$ (95\% Cl $31.3 \%$ to $45.5 \%)$. Having a greater comorbidities ( $\mathrm{OR}=6.17 ; 95 \% \mathrm{Cl} 1.44$ to 26.43$)$, drinking alcohol (OR=3.86; $95 \% \mathrm{Cl} 1.02$ to 14.59$)$ and obtaining health information from health workers $(0 \mathrm{R}=3.77 ; 95 \%$ Cl 1.22 to 11.66) were positively associated with the prevalence of psychological distress. By contrast, being overweight $(\mathrm{OR}=0.29 ; 95 \% \mathrm{Cl} 0.09$ to 0.93$)$, adopting books as the primary source of health information ( $0 \mathrm{R}=0.11 ; 95 \% \mathrm{Cl} 0.01$ to 0.8$)$, and receiving a higher number of home visits by community health workers (CHWs) (OR=0.38; 95\% Cl 0.14 to 0.99 ) were negatively associated with the prevalence of psychological distress. Conclusion This study highlighted a high prevalence of psychological distress among mountainous farmers. Providing routine psychological and physical health screening, developing CHWs to provide clinical support and raising health awareness are critical implications for reducing psychological distress in this population.

\section{INTRODUCTION}

Psychological distress covers 'a wide spectrum, ranging from normal feelings of

\section{Strengths and limitations of this study}

- The use of a structured questionnaire and face-toface interviews were appropriate to estimate the prevalence and factors associated with psychological distress.

- A comprehensive statistical analysis was performed to determine factors related to psychological distress status and the Kessler Psychological Distress Scale (K6) scores.

- Although the K6 scale has been widely used for examining psychological distress, it has not been validated for mountainous farmers in Vietnam.

- The cross-sectional study design in which the cause-effect relationship between psychological distress and independent variables was not clarified.

- The small sample size might not represent farmers residing in the mountainous setting of Vietnam as a whole.

vulnerability, sadness and fears to problems that can become disabling, such as depression, anxiety, extensive worries, negative thoughts or social isolation'. ${ }^{1}$ Psychological distress has been known to be associated with multiple factors encompassing socioeconomic disadvantages, ${ }^{2-4}$ geographical settings, ${ }^{5}$ occupations ${ }^{67}$ and physical conditions. ${ }^{89}$ Previous studies of the prevalence of psychological distress in developing countries are inconsistent, broadly ranged from $5.4 \%$ to $52.5 \% .{ }^{3}{ }^{10}$ Moreover, people engaged in agriculture faced higher risk and prevalence of psychological distress, ${ }^{7}$ which probably contributed to a high rate of suicide attempts among them. ${ }^{11} 12$

Farming has been well documented as a physically and mentally demanding work. ${ }^{13}$ Besides, farming has suffered from pressure in the form of poverty, insect and disease outbreaks, globalisation, ${ }^{14}$ drought and severe 
weather due to climate change ${ }^{15}$ and toxic exposure. ${ }^{16}$ Notably, farmers residing in remote mountainous locations are more often isolated geographically and socially from services. ${ }^{1317-19}$ Accordingly, they are highly likely to suffer from physical diseases as well as poorer psychological health. ${ }^{1320}$ These issues may reduce productivity and place a great economic burden on this vulnerable population. Studying determinants of psychological distress among farmers in the mountainous setting is, therefore, essential to develop contextualised interventions for the enhancement of their well-being.

In Vietnam, approximately $48 \%$ of the total population is involved in agriculture. Among them, $89 \%$ are small household farmers, of which more than $65 \%$ are located in rural and mountainous regions. ${ }^{21}$ Therefore, developing strategies to improve the physical and mental health of farmers in the mountainous setting is important to bridge the health-inequality gap in Vietnam. However, very limited research has been available on the psychological distress of this population. This study, therefore, aims to examine the prevalence and risk factors related to psychological distress among farmers in a typical mountainous province in Vietnam.

\section{METHODS}

\section{Study design and setting}

A cross-sectional study was performed from August to September 2018 in Moc Chau-Son La, a remote mountainous region in the Northwest of Vietnam. Moc Chau covers a land area of approximately $1081 \mathrm{~km}^{2}$. The population is 104 730, of which ethnic minorities account for $61.53 \%$ of the population, and $11.11 \%$ live under the national poverty level. ${ }^{21}$ By 2014, 5 out of 15 communes had reached the national criteria for healthcare with 3.5 doctors per 10000 resident population and one district hospital with 150 inpatient beds. ${ }^{21}$

To conduct this study, we used computer software to randomise 200 households within a full list of households in Moc Chau. Subsequently, we randomly approached one individual from each selected household, explained the study and requested participation. The eligibility criteria were that residents aged at least 18 years, spoke Vietnamese, were residing in Moc Chau at the time of interviewing and consented to take part in the study. We excluded those who suffered from severe diseases during the selection process. Ultimately, among 200 eligible farmers who were invited into the study, 3 of them refused to participate in this study, resulting in a total of 197 farmers participated in the survey (response rate $98.5 \%$ ). All of them completed the survey, and their data were used for analysis (completion rate 100\%).

\section{Measurements and instruments}

Data were collected through a 10-minute face-to-face interview performed by well-trained researchers. We did not include healthcare employees in commune health stations in the recruitment process and the data collection team.

In order to address confidentiality concerns, enrolled subjects were interviewed in a private counselling room at commune health stations. Participants were provided with detailed information about the purpose of the study, benefits as well as drawbacks of participation. Participants were also required to sign written informed consent. Twenty participants of different ages and genders were enrolled in a pilot survey. The description of the questions in the survey was then amended to suit the participants' preferences and culture.

\section{Psychological distress}

The six-item Kessler Psychological Distress Scale (K6) was used to screen and measure non-specific psychological distress among the participants. This scale has yielded high internal consistency and reliability and has been validated in several populations in the USA, Korea and Hong Kong. ${ }^{22-24}$ Participants were asked to rate how frequently they experienced distress consisting of nervous, hopeless, restless or fidgety, depressed, think that everything was an effort and worthless during the last 30 days prior to taking the survey. These six dimensions were assessed using the five-point Likert scale including ' $0=$ none of the time', ' $1=\mathrm{a}$ little of the time', ' $2=$ some of the time', ' $3=$ most of the time' or ' $4=$ all of the time', respectively. Responses were summed to obtain the total score, ranging from 0 to 24 . A previous study showed that a cut point on $\geq 13$ on the $\mathrm{K} 6$ was optimal for assessing the prevalence of serious psychological distress. ${ }^{25}$

\section{Sociodemographic characteristics}

Participants were asked to report their sociodemographic information related to age, gender, ethnicity, marital status, number of family members and monthly household income. In terms of educational level, participants were divided into three categories: none/under secondary school (under grade 6), secondary school (grades 6-9) and upper secondary school/higher degree (grades 10-12 or higher degree).

\section{Health status}

We collected data related to weight status and current physical diseases. Based on the WHO body mass index (BMI, in $\mathrm{kg} / \mathrm{m}^{2}$ ) cut point, weigh status was categorised into three groups: underweight: $<18.5 \mathrm{~kg} / \mathrm{m}^{2}$, normal weight: $18.5-24.9 \mathrm{~kg} / \mathrm{m}^{2}$ and overweight: $\geq 25 \mathrm{~kg} / \mathrm{m}^{2}$.

Participants reported their morbidities by answering the question: 'Are you currently suffering from any diseases?'. Diseases could be non-communicable or infectious diseases.

\section{Health behaviours}

Regarding smoking behaviour, participants were grouped as 'ever smoker' group if they had smoked at least 100 cigarettes in their lifetime. In terms of drinking, participants were classified as 'drink alcohol' if they had drunk wine or beer. Besides, participants also reported the total 
time spent on household chores and sports activities (ie, walking, swimming, jogging, cycling, dancing, playing badminton, playing tennis, playing football or other sports activities) per day.

\section{Services utilisation}

Data about primary sources of health information (friend/relative, internet, radio/television, local speaker, book, healthcare workers, social network), the availability of community health workers (CHWs) at their residential places (yes/no) and the number of home visits by CHWs (times over last 12 months) were also collected via this survey.

\section{Statistical analysis}

We used STATA V.12 to perform statistical analysis. A p value $<0.05$ was regarded as statistical significance. The univariate and multivariate logistic and tobit regression models were employed to determine factors related to psychological distress status and the K6 score. For the logistic regression, the main outcome variable was whether the participants suffered from psychological distress; and the dependent variables for tobit regression were the K6 scores.

\section{Patient and public involvement}

Patients or the public were not involved in the design, or conduct, or reporting or dissemination plans of our research.

\section{RESULTS}

Table 1 shows that the majority of respondents was ethnic minorities $(69.6 \%)$, married $(91.1 \%)$ and approximately half of them $(41.8 \%)$ had low educational attainment (ie, under secondary school). The mean age, number of household members and monthly household income of them were 44.9 years, 4.5 and US $\$ 253.7$, respectively. Participants also reported that they spent 2.8 hours/day doing household chores and 1.4 hours/day doing sports activities.

The prevalence of psychological distress among 197 respondents was $38.2 \%$ (95\% CI $31.3 \%$ to $45.5 \%$ ), while $59.9 \%$ (95\% CI $52.7 \%$ to $66.8 \%$ ) of them reported that they did not have any diseases (table 2).

Table 2 also indicates that the mean K6 score was 4.1 (95\% CI $3.4 \%$ to $4.7 \%$ ). The three most frequent symptoms of psychological distress were nervous $(62.9 \%$; $95 \%$ CI $55.8 \%$ to $69.7 \%$ ), restless or fidgety $(43.1 \%$; $95 \%$ CI $36.0 \%$ to $50.3 \%)$ and 'think everything was an effort' $(40.9 \%$; $95 \%$ CI $33.9 \%$ to $48.2 \%)$.

Figure 1 depicts the primary source of health information among participants. Most of them reported that they obtained health information from radio or television $(74.4 \%)$ and medical staff $(26.7 \%)$ when purchasing medications. Participants without psychological distress more frequently sought health-related information from books compared with their counterparts.
Table 1 Sociodemographic and behaviour of respondents $(\mathrm{N}=197)$

\begin{tabular}{|c|c|c|}
\hline \multirow[b]{2}{*}{ Characteristics } & \multicolumn{2}{|l|}{ Total } \\
\hline & $\mathbf{N}$ & $\%$ \\
\hline \multicolumn{3}{|l|}{ Age group } \\
\hline$<30$ & 19 & 10.0 \\
\hline $30-40$ & 52 & 27.2 \\
\hline $41-50$ & 58 & 30.4 \\
\hline$>50$ & 62 & 32.5 \\
\hline \multicolumn{3}{|l|}{ Gender } \\
\hline Male & 95 & 49.7 \\
\hline Female & 96 & 50.3 \\
\hline \multicolumn{3}{|l|}{ Ethnic } \\
\hline Kinh & 58 & 30.4 \\
\hline Others & 133 & 69.6 \\
\hline \multicolumn{3}{|l|}{ Education } \\
\hline None/under secondary school & 79 & 41.8 \\
\hline Secondary school & 75 & 39.7 \\
\hline Upper secondary school/higher degree & 35 & 18.5 \\
\hline \multicolumn{3}{|l|}{ Marital status } \\
\hline Married & 173 & 91.1 \\
\hline Others & 17 & 9.0 \\
\hline \multicolumn{3}{|l|}{ Health behaviour } \\
\hline Ever smoker & 51 & 27.0 \\
\hline \multirow[t]{2}{*}{ Drink alcohol } & 101 & 53.4 \\
\hline & Mean & SD \\
\hline Age & 44.9 & 11.8 \\
\hline Monthly household income (US\$) & 253.7 & 211.8 \\
\hline Number of family members & 4.5 & 1.9 \\
\hline Hours per day doing household chores & 2.8 & 3.1 \\
\hline Hours per day doing sports activities & 1.4 & 1.8 \\
\hline
\end{tabular}

Table 3 reports the results of the univariate and multivariate regression models presenting the associated factors with the psychological distress of respondents.

At the significance level of 5\%, farmers who had drunk alcohol were 3.86 times higher risk of having psychological distress (OR=3.86, 95\% CI 1.02 to 14.59) and higher in the $\mathrm{K} 6$ score (coefficient $=3.31,95 \%$ CI 0.64 to 5.97) than those who never drank. Participants who had multiple concurrent diseases were 6.17 times more likely to suffer from psychological distress $(\mathrm{OR}=6.17,95 \%$ CI 1.44 to 26.43$)$. Furthermore, they had 4.32 points higher in the K6 score (coefficient $=4.32,95 \%$ CI 1.57 to 7.07 ). The likelihood of psychological distress among participants achieving health information from healthcare workers was 3.77 times higher than those who did not obtain information from this source $(\mathrm{OR}=3.77,95 \%$ CI 1.22 to 11.66). By contrast, the use of books as a source of health information negatively associated with the prevalence of mental distress ( $\mathrm{OR}=0.11,95 \%$ CI 0.01 to 


\begin{tabular}{|c|c|c|c|}
\hline Characteristics & $\mathbf{n}$ & $\%$ & $95 \% \mathrm{Cl}$ \\
\hline \multicolumn{4}{|l|}{ Weight status } \\
\hline Underweight & 8 & 5.1 & 2.2 to 98.5 \\
\hline Normal & 99 & 63.5 & 55.4 to 71.0 \\
\hline Overweight & 49 & 31.4 & 24.2 to 39.3 \\
\hline \multicolumn{4}{|l|}{ Comorbidity } \\
\hline Do not have disease & 118 & 59.9 & 52.7 to 66.8 \\
\hline Have one disease & 50 & 25.4 & 19.5 to 32.1 \\
\hline Have more than one disease & 29 & 14.7 & 10.1 to 20.5 \\
\hline \multicolumn{4}{|l|}{ Feeling in the past 30 days } \\
\hline Nervous & 124 & 62.9 & 55.8 to 69.7 \\
\hline Hopeless & 44 & 22.3 & 16.7 to 28.8 \\
\hline Restless or fidgety & 84 & 43.1 & 36.0 to 50.3 \\
\hline Depressed & 55 & 28.4 & 22.1 to 35.2 \\
\hline Think everything was an effort & 79 & 40.9 & 33.9 to 48.2 \\
\hline Feel worthless & 42 & 21.5 & 16.0 to 28.0 \\
\hline \multicolumn{4}{|l|}{ Psychological distress } \\
\hline Normal & 118 & 61.8 & 54.5 to 68.7 \\
\hline \multirow[t]{2}{*}{ Psychological distress } & 73 & 38.2 & 31.3 to 45.5 \\
\hline & Mean & SD & $95 \% \mathrm{Cl}$ \\
\hline $\begin{array}{l}\text { Kessler psychological distress } \\
\text { scale score }\end{array}$ & 4.1 & 4.2 & 3.4 to 4.7 \\
\hline
\end{tabular}

$0.81)$. Being overweight had significantly lower risk of psychological distress ( $\mathrm{OR}=0.29,95 \%$ CI 0.09 to 0.93 ) and $\mathrm{K} 6$ score (coefficient $=-3.44,95 \%$ CI -5.90 to -0.99 ) compared with those who were at normal weight. Also, the frequency of home visits by CHWs was negatively associated with psychological distress $(\mathrm{OR}=0.38,95 \%$ CI 0.14 to 0.99$)$.

\section{DISCUSSION}

To our knowledge, this is among the first studies that investigated the psychological distress of farmers residing in the mountainous region of Vietnam. Our study highlighted a high prevalence of psychological distress among

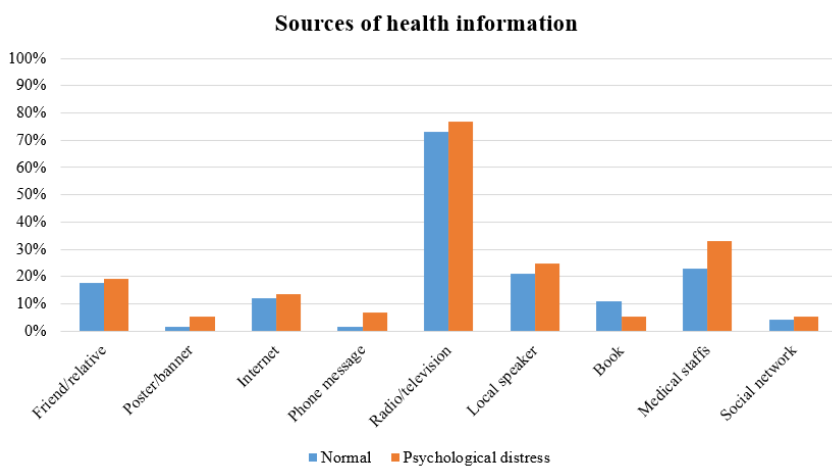

Figure 1 Source of health information. farming mountain dwellers. Furthermore, we found that drinking alcohol, having a higher number of multiple concurrent diseases and obtaining health information from healthcare workers were positively associated with the prevalence of psychological distress. By contrast, being overweight, adopting books as the primary source of health information and receiving a higher number of home visits by CHWs were all negatively associated with the prevalence of psychological distress. These findings provide useful insights into developing healthcare programmes in the mountainous sites in Vietnam.

The high prevalence of psychological distress found in our study was in line with the results of prior studies using the $\mathrm{K} 6$ instrument, conducted in rural areas in lowincome and middle-income countries including Nigeria $(35.5 \%)$, Uganda $(30.8 \%)$ and Ghana $(30.8 \%) .{ }^{26}$ It was also relatively similar to that found among farmers in Thailand (38.8\% in women vs $28.8 \%$ in men), ${ }^{27}$ China $(31.13 \%)^{11}$ and Brazil (33.8\%).$^{28}$ Nevertheless, the prevalence of psychological distress found in this study was approximately 2.5-7 times higher compared with the results of previous studies conducted in Vietnam. ${ }^{3} 29$ Such wide discrepancies might be a result of methodological differences in sampling, settings and measurement instruments applied. First, other studies centred on the general Vietnamese population, whereas ours targeted farmers specifically. The prevalence of psychological distress among farmers, on the other hand, was reported to be higher than that in the general population in some other jurisdictions. ${ }^{30-33}$ Second, while our study was undertaken in a remote mountainous area, the others were performed in either the urban or the metropolitan countryside. Finally, selecting different measurement instruments and cut-off points were also attributable to the divergence of results. The high prevalence of psychological distress in this sample suggests that screening and monitoring of psychological health status should be implemented across various occupations and geographical settings in Vietnam.

In this study, we found that acquiring health information from healthcare providers was positively associated with the prevalence of psychological distress. We presume the underlying cause of this phenomenon is that in our sample, the majority of farmers merely went to visit and to achieve health information from medical professionals once they had severe health problems. Indeed, our hypothesis was supported by previous studies that showed approximately $50 \%-80 \%$ of inhabitants in rural and mountainous sites of Vietnam habitually practised selftreatment or self-medication ${ }^{34-36}$ or visited nearby traditional healers. ${ }^{37} 38$ Additionally, our regression model indicated that multiple concurrent diseases were statistically linked to psychological distress. This was also consistent with studies that confirmed the positive relationship between the number of physical diseases and psychological distress. ${ }^{39} 40$ This finding suggests that improving interventions to prevent physical illness would possibly reduce the risk of psychological distress. 


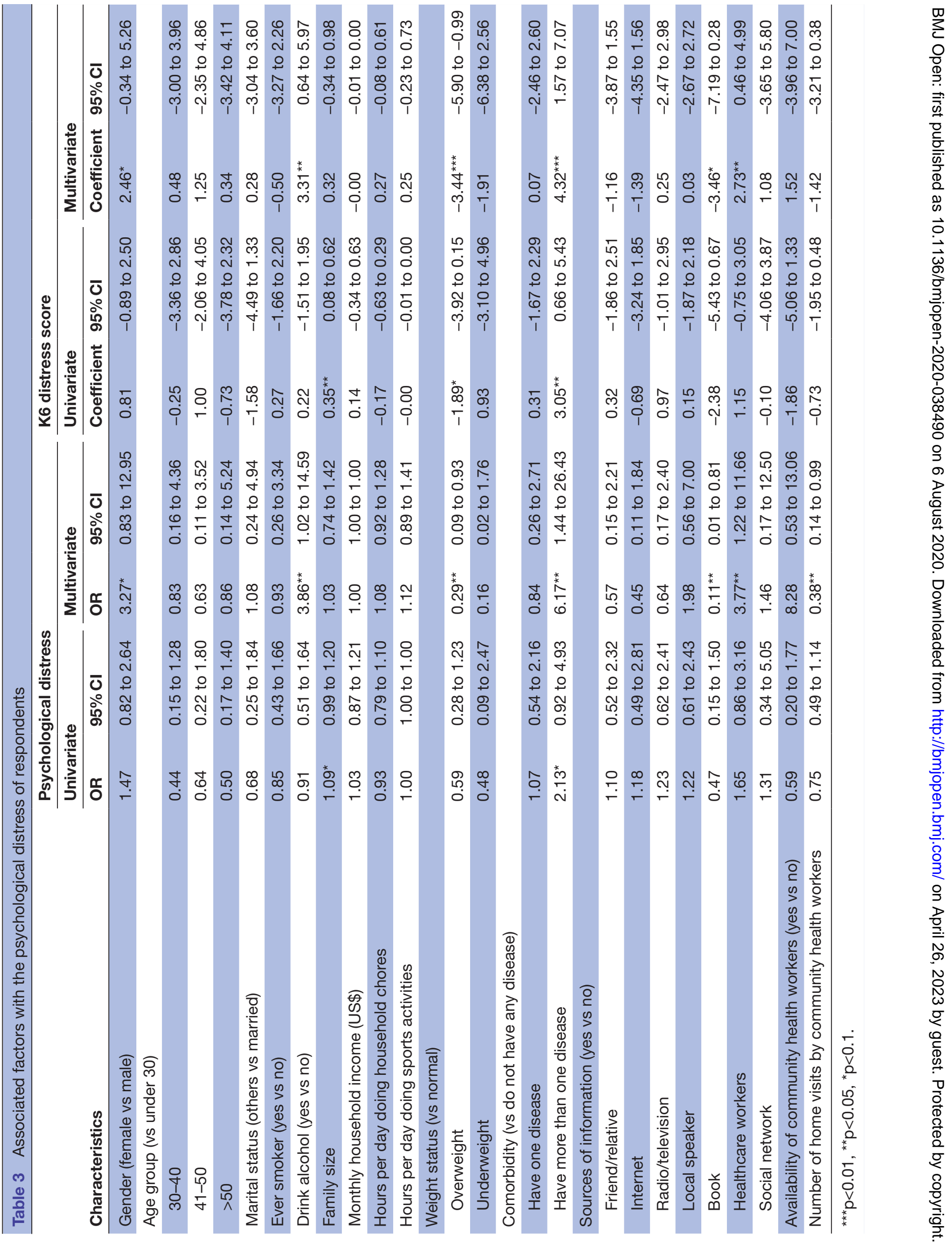


This study revealed that adopting books as the source of health information was negatively associated with the prevalence of psychological distress. We observed that people with higher educational attainment tended to actively seek information from books than those with a lower level of education. Educated people might, therefore, be equipped with valuable insights into adopting a better lifestyle to prevent psychological and physical health problems. The analysis also indicated that drinking was significantly associated with a higher risk of having psychological distress. This finding was supported by previous studies that demonstrated a positive association between the level of alcohol consumption and psychological distress. ${ }^{41}{ }^{42}$ Our findings, therefore, suggested that promoting health literacy and a healthy lifestyle may reduce the risk of psychological distress among farmers in the mountainous region. Notably, our results also showed that a higher frequency of home visits by CHWs reduced the risk of psychological distress. In the mountainous areas of Vietnam, CHWs are more than health workers; they are also neighbours and friends with their patients since they usually live in the same hamlets or villages with their patients. ${ }^{43}$ Within the context of Vietnam, it is thus appropriate to enhance the capability of CHWs in providing clinical support and raising health awareness of farmers in disadvantaged areas through appropriate training and education.

It is also worth noting that being overweight significantly associated with a lower risk of psychological distress and K6 scores. This result might conflict with the conclusion of several studies demonstrating higher BMI increased the risk of psychological distress in developed countries. ${ }^{44-46}$ However, similar to findings in China and Taiwan, this negative association could be partially explained by the common cultural background in which the correlation between mental health and being overweight was described as 'laughing and growing fat is happiness'. Many people, therefore, tended to gain weight in later years as a result of their good fortune. ${ }^{4-49}$ Greater weight may also be an indicator of economic status in this population. However, due to the controversial relationship between being overweight and psychological distress, we suggest conducting further studies to elucidate associated factors underlying this anecdotal evidence.

There are a number of limitations that this study contains. First, since we did not apply any diagnostic instrument for psychiatric disorders, the specific type of psychological distress such as normal emotional distress or pathological conditions could not be identified. As a result, not all individuals with psychological distress found in this study were candidates for medicalised intervention. Further studies are needed to determine whether or not farmers with psychological distress would benefit from psychotherapy or medication interventions. Second, although the K6 scale has been globally used for examining psychological distress, it has not been validated for mountainous farmers in Vietnam. Third, the use of self-reported morbidity information might cause recall bias as well as underestimate comorbidities due to undiagnosed conditions. Also, our study shared the common limitation of cross-sectional study design in which the causeeffect relationship between psychological distress and independent variables was not clarified. Finally, due to the small sample size, our sample might not represent farmers residing in the mountainous setting of Vietnam as a whole.

\section{CONCLUSION}

This study expands the existing literature on the high prevalence of psychological distress among farmers residing in the remote mountainous setting in Vietnam. A number of factors were found to be associated with psychological distress among this vulnerable population. These findings underline a need for integrating psychological and physical prevention services. Providing routine psychological and physical health screening, treatment, enhancing the capability of CHWs in providing clinical support and raising health awareness are all important implications for reducing psychological distress in this population.

\section{Author affiliations}

${ }^{1}$ Institute for Global Health Innovations, Duy Tan University, Da Nang, Viet Nam

${ }^{2}$ Faculty of Pharmacy, Duy Tan University, Da Nang, Viet Nam

${ }^{3}$ Institute for Preventive Medicine and Public Health, Hanoi Medical University, Hanoi, Viet Nam

${ }^{4}$ Faculty of Medicine, Duy Tan University, Da Nang, Viet Nam

${ }^{5}$ Center of Excellence in Evidence-Based Medicine, Nguyen Tat Thanh University, Ho Chi Minh, Viet Nam

${ }^{6}$ Bloomberg School of Public Health, Johns Hopkins University, Baltimore, Maryland, United States

${ }^{7}$ Department of Psychological Medicine, Yong Loo Lin School of Medicine, National University of Singapore, Singapore

${ }^{8}$ Institute for Health Innovation and Technology (iHealthtech), National University of Singapore, Singapore

${ }^{9}$ Department of Psychological Medicine, National University Hospital, Singapore

Acknowledgements We would like to express our gratitude to the residents in Moc Chau province for participating and supporting us to perform this study.

Contributors Conceptualisation: MTH, KND, GHH, RCMH and CSHH; data curation: KND, HQP, CTN and GHH; formal analysis: MTH, HQP and GTV; investigation: MTH, KND, HQP and CTN; methodology: BXT and HQP; software: CTN; supervision: CSHH, RCMH and CL; validation: BXT and CL; writing—original draft: MTH, KND and GTV; writing — review and editing: MTH, GTV, BXT, RCMH and CSHH.

Funding The authors have not declared a specific grant for this research from any funding agency in the public, commercial or not-for-profit sectors.

Competing interests None declared.

Patient consent for publication Obtained.

Ethics approval The protocol of the study was reviewed and approved by the Institutional Review Board of Hanoi Medical University (code: 20/HMUIRB).

Provenance and peer review Not commissioned; externally peer reviewed.

Data availability statement Data are available upon reasonable request.

Open access This is an open access article distributed in accordance with the Creative Commons Attribution Non Commercial (CC BY-NC 4.0) license, which permits others to distribute, remix, adapt, build upon this work non-commercially, and license their derivative works on different terms, provided the original work is 
properly cited, appropriate credit is given, any changes made indicated, and the use is non-commercial. See: http://creativecommons.org/licenses/by-nc/4.0/.

\section{ORCID iDs}

Hai Quang Pham http://orcid.org/0000-0003-4448-5436

Giang Hai Ha http://orcid.org/0000-0001-8682-258X

Roger C M Ho http://orcid.org/0000-0001-9629-4493

\section{REFERENCES}

1 Zimmermann T. Cancer: psychosocial aspects. In: Wright JD, ed. International encyclopedia of the social \& behavioral sciences. 2nd edn. Oxford: Elsevier, 2015: 73-7.

2 Erdem Özcan, Van Lenthe FJ, Prins RG, et al. Socioeconomic inequalities in psychological distress among urban adults: the moderating role of neighborhood social cohesion. PLoS One 2016;11:e0157119.

3 Bao Giang K, Viet Dzung T, Kullgren G, et al. Prevalence of mental distress and use of health services in a rural district in Vietnam. Glob Health Action 2010;3:2025.

4 Butterworth P, Olesen SC, Leach LS. The role of hardship in the association between socio-economic position and depression. Aust N Z J Psychiatry 2012;46:364-73.

5 Stickley A, Koyanagi A, Roberts B, et al. Urban-rural differences in psychological distress in nine countries of the former Soviet Union. $J$ Affect Disord 2015;178:142-8.

6 Sanne B, Mykletun A, Dahl AA, et al. Occupational differences in levels of anxiety and depression: the Hordaland health study. $J$ Occup Environ Med 2003;45:628-38.

7 Sanne B, Mykletun A, Moen BE, et al. Farmers are at risk for anxiety and depression: the Hordaland health study. Occup Med 2004:54:92-100.

8 Backe IF, Patil GG, Nes RB, et al. The relationship between physical functional limitations, and psychological distress: considering a possible mediating role of pain, social support and sense of mastery. SSM Popul Health 2018;4:153-63.

9 Goldberg D. The detection and treatment of depression in the physically ill. World Psychiatry 2010;9:16-20.

10 Islam FMA. Psychological distress and its association with sociodemographic factors in a rural district in Bangladesh: a crosssectional study. PLoS One 2019;14:e0212765.

11 Feng D, Ji L, Xu L. Effect of subjective economic status on psychological distress among farmers and non-farmers of rural China. Aust J Rural Health 2015;23:215-20.

12 Gregoire A. The mental health of farmers. Occup Med 2002;52:471-6.

13 Brew B, Inder K, Allen J, et al. The health and wellbeing of Australian farmers: a longitudinal cohort study. BMC Public Health 2016;16:988.

14 Peck DF, Grant S, McArthur W, et al. Psychological impact of footand-mouth disease on farmers. J Ment Health 2002;11:523-31.

15 Berry HL, Hogan A, Owen J, et al. Climate change and farmers mental health: risks and responses. Asia Pac J Public Health 2011;23:119S-32.

16 Hu R, Huang X, Huang J, et al. Long- and short-term health effects of pesticide exposure: a cohort study from China. PLoS One 2015;10:e0128766.

17 Casey MM, Thiede Call K, Klingner JM. Are rural residents less likely to obtain recommended preventive healthcare services? Am J Prev Med 2001;21:182-8.

18 Fuller J, Edwards J, Procter N, et al. How definition of mental health problems can influence help seeking in rural and remote communities. Aust J Rural Health 2000;8:148-53.

$19 \mathrm{Ng} \mathrm{N}$, Hakimi M, Byass P, et al. Health and quality of life among older rural people in Purworejo district, Indonesia. Glob Health Action 2010;3:2125

20 Cross P, Edwards RT, Nyeko P, et al. The potential impact on farmer health of enhanced export horticultural trade between the U.K. and Uganda. Int J Environ Res Public Health 2009;6:1539-56.

21 Papadakaki M, Tsalkanis A, Sarris M, et al. Physical, psychological and economic burden of two-wheel users after a road traffic injury: evidence from intensive care units of three EU countries. J Safety Res 2018;67:155-63.

22 Kessler RC, Andrews G, Colpe LJ, et al. Short screening scales to monitor population prevalences and trends in non-specific psychological distress. Psychol Med 2002;32:959-76.

$23 \mathrm{Min}$ JW, Lee SH. Validation of the K6/K10 scales of psychological distress and their optimal cutoff scores for older Koreans. Int J Aging Hum Dev 2015:80:264-82.
24 Chan SM, Fung TCT. Reliability and validity of K10 and K6 in screening depressive symptoms in Hong Kong adolescents. Vulnerable Child Youth Stud 2014;9:75-85.

25 Kessler RC, Barker PR, Colpe LJ, et al. Screening for serious mental illness in the general population. Arch Gen Psychiatry 2003;60:184-9.

26 Sweetland AC, Norcini Pala A, Mootz J, et al. Food insecurity, mental distress and suicidal ideation in rural Africa: evidence from Nigeria, Uganda and Ghana. Int J Soc Psychiatry 2019;65:20-7.

27 Hanklang S, Kaewboonchoo O, Morioka I, et al. Gender differences in depression symptoms among rice farmers in Thailand. Asia Pac J Public Health 2016;28:83-93.

28 Poletto Ângela Regina, Gontijo LA. Family farming workers mental health in a microrregion in southern Brazil. Work 2012;41(Suppl 1):4987-94.

29 Vuong DA, Van Ginneken E, Morris J, et al. Mental health in Vietnam: burden of disease and availability of services. Asian J Psychiatr 2011;4:65-70.

30 Fragar LHA, Morton C, Pollock K. The mental health of people on Australian farms - the facts. Rural industries research and development Corporation and Australian centre for agricultural health and safety, 2008.

31 Andersen $\mathrm{K}$, Hawgood J, Klieve $\mathrm{H}$, et al. Suicide in selected occupations in Queensland: evidence from the state suicide register. Aust N Z J Psychiatry 2010;44:243-9.

32 Fragar L, Stain HJ, Perkins D, et al. Distress among rural residents: does employment and occupation make a difference? Aust J Rural Health 2010;18:25-31.

33 Jones-Bitton A, Best C, MacTavish J, et al. Stress, anxiety, depression, and resilience in Canadian farmers. Soc Psychiatry Psychiatr Epidemiol 2020;55:229-36.

$34 \mathrm{Ha} \mathrm{TV}$, Nguyen AMT, Nguyen HST. Self-medication practices among Vietnamese residents in highland provinces. J Multidiscip Healthc 2019;12:493-502.

35 Toan NV, Trong LN, Höjer B, et al. Public health services use in a mountainous area, Vietnam: implications for health for policy. Scand J Public Health 2002;30:86-93.

36 Okumura J, Wakai S, Umenai T. Drug utilisation and self-medication in rural communities in Vietnam. Soc Sci Med 2002;54:1875-86.

37 Tran BX, Nguyen LH, Nong VM, et al. Health status and health service utilization in remote and mountainous areas in Vietnam. Health Qual Life Outcomes 2016;14

38 Woerdenbag HJ, Nguyen TM, Vu DV, et al. Vietnamese traditional medicine from a pharmacist's perspective. Expert Rev Clin Pharmacol 2012;5:459-77.

39 Byles JE, Robinson I, Banks E, et al. Psychological distress and comorbid physical conditions: disease or disability? Depress Anxiety 2014;31:524-32

40 Thakur ER, Quigley BM, El-Serag HB, et al. Medical comorbidity and distress in patients with irritable bowel syndrome: the moderating role of age. J Psychosom Res 2016;88:48-53.

41 Obadeji A, Oluwole LO, Dada MU, et al. Alcohol use and psychological wellbeing of health workers in a Nigerian Hospital: an exploratory study. Malawi Med J 2018;30:31-6.

42 Balogun O, Koyanagi A, Stickley A, et al. Alcohol consumption and psychological distress in adolescents: a multi-country study. $J$ Adolesc Health 2014;54:228-34.

43 Tran BX, Phan HT, Nguyen TPT, et al. Reaching further by village health collaborators: the informal health Taskforce of Vietnam for COVID-19 responses. J Glob Health 2020;10:010354-54.

$44 \mathrm{Gu}$ JK, Charles LE, Burchfiel CM, et al. Associations between psychological distress and body mass index among law enforcement officers: the National health interview survey 2004-2010. Saf Health Work 2013;4:52-62.

45 Scott KM, McGee MA, Wells JE, et al. Obesity and mental disorders in the adult general population. J Psychosom Res 2008;64:97-105.

46 Stanley SH, Laugharne JDE, Addis S, et al. Assessing overweight and obesity across mental disorders: personality disorders at high risk. Soc Psychiatry Psychiatr Epidemiol 2013;48:487-92.

47 Zhang L, Liu K, Li H, et al. Relationship between body mass index and depressive symptoms: the "fat and jolly" hypothesis for the middle-aged and elderly in China. BMC Public Health 2016;16:1201-01.

48 Chang $\mathrm{H}-\mathrm{H}$, Yen ST. Association between obesity and depression: evidence from a longitudinal sample of the elderly in Taiwan. Aging Ment Health 2012;16:173-80.

49 Yu N-W, Chen C-Y, Liu C-Y, et al. Association of body mass index and depressive symptoms in a Chinese community population: results from the health promotion knowledge, attitudes, and performance survey in Taiwan. Chang Gung Med J 2011;34:620-7. 